Research Paper

\title{
Enterotoxigenicity of Staphylococcus aureus isolated from traditional and commercial dairy products marketed in Iran
}

\author{
Ebrahim Rahimi \\ Department of Food Hygiene, College of Veterinary Medicine, Islamic Azad University, \\ Shahrekord Branch, Shahrekord, Iran.
}

Submitted: October 5; Approved: July 23, 2012.

\begin{abstract}
This study was conducted to determine the prevalence rate, enterotoxigenecity, and antimicrobial resistance of S. aureus isolated from dairy products in Iran. From September 2010 to July 2011, a total of 347 samples from various dairy products, traditional and commercial, were collected from randomly selected retail stores. Overall, 20 samples $(5.8 \%)$ were found to be contaminated with $S$. aureus. The highest prevalence of S. aureus was found in traditional cheese (11.1\%), followed by traditional ice-cream (5.9\%), cream (5.6\%), and butter (5.3\%). The ability to synthesize classical staphylococcal enterotoxins (SEA-E) was determined in 7 of $20(35 \%)$ isolates by using ELISA. SE type C was the most common enterotoxin found in the isolated S. aureus (42.9\%), followed by SE type A (28.6\%), SEA+SEC and SE type D (14.3\%). Of the 20 isolates, 16 (80.0\%) were positive for one or more entrotoxin genes and 8 different genotypes were observed. Susceptibilities of the isolates were determined for 14 antimicrobial drugs using the disk diffusion assay. Most of the isolates (95.0\%) were resistant to one or more two antimicrobial agent and $45.0 \%$ of the isolates were resistant to three or more of drugs. Resistance to ampicillin was the most common finding $(55.0 \%)$, followed by tetracycline $(40.0 \%)$ and penicillin $\mathrm{G}(30.0 \%)$. The results of this study showed the wide spread of enterotoxigenic and multidrug-resistant $S$. aureus strains in traditional dairy products in Iran and highlighted their public health hazards.
\end{abstract}

Key words: antimicrobial resistance, dairy products, SE genes, staphylococcal enterotoxins, Staphylococcus aureus.

\section{Introduction}

Staphylococci are ubiquitous in nature; although the primary reservoir is on the skin and mucous membranes of mammals and birds. The presence of Staphylococcus aureus (S. aureus) in products for human consumption is important to the food industry as some strains are the cause of foodborne intoxication (Pelisser et al., 2009). The genus Staphylococci includes over 30 species; whit 18 of these species and subspecies are of potential hazard in food poisoning as they produce either coagulase, heat stable nuclease or enterotoxins. The coagulase positive species are $S$. aureus subsp. aureus which is the most common enterotoxigenic species (Le Loir et al., 2003, Loncarevic et al., 2005). S. aureus is a common pathogen associated with se- rious community and hospital acquired diseases and has for long been considered as a major problem of public health (Pesavento et al., 2007).

The pathogenicity of $S$. aureus and its ability to cause diseases is attributed to a number of virulence factors such as the heat stable enterotoxins (Sandel and McKillip, 2004). S. aureus produces 15 enterotoxins (Atichou et al., 2004). The five classical enterotoxins (SE, type A, B, C, D and $\mathrm{E}$ ) were known to be responsible for $95 \%$ of staphylococcal food poisoning (SFP) cases, the rest of cases were due to the new types of SEs (SEG-SEO) (Jay et al., 2005). However, the role of newly identified enterotoxins in food poisoning is not fully clarified, and the development of methods for the detection of these novel se genes is of critical importance for food poisoning investigations. 
SFP is a mild intoxication occurring after the ingestion of food containing from $20 \mathrm{ng}$ to $1 \mu \mathrm{g}$ of staphylococcal enterotoxin (SE) which is enough to induce symptoms in human beings (Normanno et al., 2007). SFP symptoms appear 1-6 h after ingestion of contaminated food, depending on individual susceptibility and toxic dose ingested. They include nausea, abdominal cramps, diarrhoea and a characteristic projectile vomiting. Clinical signs of SFP generally disappear within 24-48 h. Deaths occur rarely and specifically in the very young or elderly (Jay et al., 2005).

Pasteurization kills $S$. aureus cells, and fermentation or ripening of cheese may prevent growth of $S$. aureus in raw milk cheese. However, once formed the thermostable SEs generally retain their biological activity (Becker et al., 2007, Le Loir et al., 2003).

Currently, there is limited information regarding the prevalence and antimicrobial susceptibility patterns of $S$. aureus in milk and dairy products in Iran. The aims of this study were to determine the prevalence rate, enterotoxigenecity, and antimicrobial resistance of S. aureus in commercial and traditional cheese, yoghurt, ice cream, butter, cream, kashk and dough in Iran. Although, governmental regulation of milk pasteurization and sanitation in dairy processing plants has been in existence in Iran for many years, direct sale of unpasteurized milk and dairy products from producers to the consumer is common in many regions including Isfahan, Chaharmahal va Bakhtyari, and Khuzestan provinces.

\section{Materials and Methods}

\section{Sample collection}

A total of 347 samples of various traditional and commercial dairy products including cheese $(\mathrm{n}=90)$, ice-cream $(\mathrm{n}=85)$, butter $(\mathrm{n}=57)$, cream $(\mathrm{n}=36)$, yoghurt $(\mathrm{n}=30)$, kashk $(n=24)$, and Iranian dough $(n=25)$ from different brands were obtained from randomly selected retail stores located in 25 major cities of Isfahan, Chaharmahal va Bakhtyari, and Khuzestan provinces From September 2010 to July 2011. Kashk and doogh are two popular dairy products in Iran that are available both as traditional and commercial products. Kashk is prepared by prolonged boiling yogurt and doogh which is also called yogurt soda is prepared by beating unflavored yogurt until smooth, and then diluting with water to a consistency similar to whole milk. Traditional dairy products in Iran are produced in small productive centers mostly located in urban areas and distributed unpacked. These products may be produced from unpasteurized milk. All samples were immediately transferred to the food microbiology laboratory, Islamic Azad University of Shahrekord Branch, in portable insulated cold-boxes. The samples were analyzed on the day they were collected.

\section{Isolation of $S$. aureus}

A $10 \mathrm{~g}$ portion of each food product was added to $90 \mathrm{~g}$ of sterile phosphate buffered saline $(137 \mathrm{mM} \mathrm{NaCl}, 10 \mathrm{mM}$ phosphate, $2.7 \mathrm{mM} \mathrm{KCl}, \mathrm{pH}$ is 7.4 ) and stomached for 30-90 s. Then microbiological processing of the samples for the isolation of $S$. aureus was performed using BairdParker agar (Difco) following a standard procedure. Decimal dilutions of sample suspensions were spread plated on the agar plates in duplicate following incubation for $24-48 \mathrm{~h}$ at $35^{\circ} \mathrm{C}$ and then finally examined for colonies with typical appearance of $S$. aureus. To identify $S$. aureus, Gram stain, catalase, coagulase, and Voges-Proskaver (VP) tests were conducted on suspected colonies (Huong et al., 2010).

\section{Detection of classical staphylococcal enterotoxins (SEs)}

To detect SEs, the isolates were cultured overnight aerobically in $10 \mathrm{~mL}$ nutrient broth (Merck, Germany) at $37^{\circ} \mathrm{C}$. Bacterial culture supernatants were collected by centrifugation at $4,000 \mathrm{x}$ f for $10 \mathrm{~min}$ and used for detection of SEA, SEB, SEC, SED, and SEE using an enzyme linked immunosorbent assay (ELISA) detection kit (RIDASCREEN® ${ }^{\circledR}$ SET A, B, C, D, E Art. No: R4101, R-Biopharm AG, Germany). The assay was performed according to the manufacturer's recommendation and as described elsewhere (Rahimi and Ghasemian Safai, 2010). The mean lower detection limit of the assay was $0.1 \mathrm{mg} / \mathrm{mL}$. All experiments were performed in duplicate.

Detection of sea, seb, sec, sed, see, seg, seh, sei, and sej

Purification of DNA was achieved using a Genomic DNA purification kit (Fermentas, GmbH, Germany) according to the manufacturer's instruction and the total DNA was measured at $260 \mathrm{~nm}$ optical density according to the method described by Sambrook and Russell (2001). After DNA isolation, amplification of selected enterotoxin genes (sea, seb, sec, sed, see, seg, seh, sei, and sej) was achieved using 9 primer sets in the one reaction mixture. The sequences of the primers used for gene amplification are presented in Table 1. All oligonucleotide primers were obtained from a commercial source (Cinna Gen, Iran). Polymerase chain reaction (PCR) assays for the detection of $S$. aureus enterotoxin genes were performed according to the methods described previously (Rall et al., 2008, Zouharova and Rysanek, 2008). Briefly, amplification reactions were performed in a $25 \mu \mathrm{L}$ mixture containing $1 \mathrm{U}$ Taq polymerase (Fermentas, GmbH, Germany), $200 \mu \mathrm{M}$ of each dNTP (Fermentas, GmbH, Germany), $2.5 \mu \mathrm{L}$ PCR buffer 10x (Fermentas, GmbH, Germany), $1.0 \mu \mathrm{M} \mathrm{MgCl}_{2}$ (Fermentas, GmbH, Germany), 10 pmol of each primers, and $3 \mu \mathrm{L}$ DNA. The final volume was adjusted to $25 \mu \mathrm{L}$ by adding sterile ultrapure water (Rall et al., 2008). Amplifica- 
Table 1 - Primers and temperature used for the detection of Staphylococcus aureus SE genes.

\begin{tabular}{|c|c|c|c|c|}
\hline Gene & Primer & Sequence & Base pair & Annealing temperature $\left({ }^{\circ} \mathrm{C}\right)$ \\
\hline \multirow[t]{2}{*}{ sea } & SEA-1 & ttggaaacggttaaaacgaa & 120 & 50 \\
\hline & SEA-2 & gaaccttcccatcaaaaaca & & \\
\hline \multirow[t]{2}{*}{ seb } & SEB-1 & tcgcatcaaactgacaaacg & 478 & 50 \\
\hline & SEB-2 & gcaggtactctataagtgcc & & \\
\hline \multirow[t]{2}{*}{$\sec$} & SEC-1 & gacataaaagctaggaattt & 257 & 50 \\
\hline & SEC-2 & aaatcggattaacattatcc & & \\
\hline \multirow[t]{2}{*}{ sed } & SED-1 & ctagtttggtaatatctcct & 317 & 50 \\
\hline & SED-2 & taatgctatatcttataggg & & \\
\hline \multirow[t]{2}{*}{ see } & SEE-1 & aggtttttcacaggtcatcc & 209 & 50 \\
\hline & SEE-2 & cttttttttcttcggtcaatc & & \\
\hline \multirow[t]{2}{*}{ seg } & SEG-1 & aagtagacatttttggegttcc & 287 & 55 \\
\hline & SEG-2 & agaaccatcaaactcgtatagc & & \\
\hline \multirow[t]{2}{*}{ seh } & SHE-1 & gtctatatggaggtacaacact & 213 & 46.4 \\
\hline & SHE-2 & gacctttacttatttcgetgtc & & \\
\hline \multirow[t]{2}{*}{ sei } & SIE-1 & ggtgatattggtgtaggtaac & 454 & 50 \\
\hline & SIE-2 & atccatattctttgectttaccag & & \\
\hline \multirow[t]{2}{*}{ sej } & SEJ-1 & catcagaactgttgttccgctag & 142 & 50 \\
\hline & SEJ-2 & ctgaattttaccatcaaaggtac & & \\
\hline
\end{tabular}

tion reactions were carried out using a DNA thermal cycler (Master Cycle Gradiant, Eppendrof, Germany) with the following program: one cycle of $5 \mathrm{~min}$ at $94^{\circ} \mathrm{C}, 30$ cycles each consisting of $45 \mathrm{~s}$ at $94^{\circ} \mathrm{C}, 1 \mathrm{~min}$ and $30 \mathrm{~s}$ at $65^{\circ} \mathrm{C}, 1 \mathrm{~min}$ at $72{ }^{\circ} \mathrm{C}$ and a final extension step of $8 \mathrm{~min}$ at $72^{\circ} \mathrm{C}$. The PCR products were stained with $1 \%$ solution of ethidium bromide and visualized under UV light after gel electrophoresis on $1.5 \%$ agarose. S. aureus ATCC 19095, ATCC 23235 and ATCC 700699 were used as the positive controls and DNase free water was used as the negative control.

\section{Antimicrobial susceptibility testing}

One colonia from each $S$. aureus-positive sample was selected for susceptibility tests. Antimicrobial susceptibility testing was performed by the Kirby-Bauer disc diffusion method using Mueller-Hinton agar (HiMedia Laboratories, Mumbai, India) supplemented with 5\% defibrinated sheep blood, according to the Clinical Laboratory Standards Institute (2006). The following antimicrobial impregnated disks (HiMedia Laboratories, Mumbai, India) were used: penicillin G (10 IU), cephalotin $(30 \mu \mathrm{g})$, chloramphenicol $(30 \mu \mathrm{g})$, clindamycin $(15 \mu \mathrm{g})$, ciprofloxacin $(30 \mu \mathrm{g})$, erythromycin $(15 \mu \mathrm{g})$, tetracycline $(30 \mu \mathrm{g})$, oxacillin $(15 \mu \mathrm{g})$, gentamycin $(10 \mu \mathrm{g})$, ampicillin $(10 \mu \mathrm{g})$, enrofloxacin $(10 \mu \mathrm{g})$, trimethoprim-sulfamethoxazole $(25 \mu \mathrm{g})$, methicillin $(5 \mu \mathrm{g})$, and vancomycin $(30 \mu \mathrm{g})$. After incubation at $37^{\circ} \mathrm{C}$ for $48 \mathrm{~h}$, the susceptibility of the $S$. aureus isolates to each antimicrobial agent was measured and the results were interpreted in accordance with interpretive criteria provided by CLSI (2006).

\section{Statistical analysis}

Data were transferred to Microsoft Excel spreadsheet (Microsoft Corp., Redmond, WA, USA) for analysis. Using SPSS 16.0 statistical software (SPSS Inc., Chicago, IL, USA), chi-square test and fisher's exact two-tailed test analysis was performed and differences were considered significant at values of $\mathrm{p}<0.05$.

\section{Results}

In the present study, a total of 347 samples of various commercial and traditional milk and dairy products were tested for enterotoxigenic $S$. aureus (Table 2). Using cultural techniques, 20 of 347 samples $(5.8 \%)$ were positive for $S$. aureus. No $S$. aureus was isolated from commercial cheese, ice cream, butter and cream samples and all yogurt, doogh, and kashk samples were negative for $S$. aureus. In contrast, 10 cheese $(11.1 \%), 5$ ice cream $(5.9 \%), 2$ cream $(5.6 \%)$ and 3 butter $(5.3 \%)$ samples were contaminated with $S$. aureus. In this study, total $S$. aureus counts determined were between $1 \times 10^{2}$ and $1 \times 10^{6} \mathrm{cfu} / \mathrm{g}$ in samples. In 3 $(6.0 \%)$ of traditional cheese, and $1(3.7 \%)$ butter samples, CPS counts were above $10^{5} \mathrm{cfu} / \mathrm{g}$ (Table 2).

The ability to synthesize classical enterotoxins was found in 7 of $20(35.0 \%)$ isolates by using ELISA technique. Two isolates produced SEA $(28.6 \%), 3$ isolates produced SEC (42.9\%), 1 isolates produced SEA+SEC $(14.3 \%)$, and 1 isolates produced SEA + SED (14.3\%) (Table 2). No SEB and SEE were identified in dairy product samples. Type A enterotoxin was found in 1 butter and 1 ice-cream samples. Type $\mathrm{C}$ and type $\mathrm{A}+\mathrm{C}$ enterotoxin was 
Table 2 - Occurrence and enterotoxigenicity of Staphylococcus aureus from traditional dairy products in Fars Iran.

\begin{tabular}{|c|c|c|c|c|c|c|c|c|c|}
\hline \multirow[t]{3}{*}{ Sources } & \multirow[t]{3}{*}{ No. of samples } & \multicolumn{3}{|c|}{ S. aureus positive samples } & \multirow[t]{3}{*}{ No. of SES } & \multicolumn{4}{|c|}{ SEs } \\
\hline & & \multirow[t]{2}{*}{ Number (\%) } & \multicolumn{2}{|c|}{ Distribution $(\mathrm{CFU} / \mathrm{G})$} & & \multirow[t]{2}{*}{ A } & \multirow[t]{2}{*}{$\mathrm{C}$} & \multirow[t]{2}{*}{$\mathrm{A}+\mathrm{C}$} & \multirow[t]{2}{*}{$\mathrm{A}+\mathrm{D}$} \\
\hline & & & $1 \times 10^{2}-1 \times 10^{4}$ & $1 \times 10^{4}-1 \times 10^{6}$ & & & & & \\
\hline Cheese & 90 & $10(11.1)$ & 7 & 3 & 4 & - & 3 & 1 & - \\
\hline Commercial cheese & 30 & - & - & - & - & - & - & - & - \\
\hline Traditional cheese ${ }^{\mathrm{a}}$ & 60 & $10(16.7)$ & 7 & 3 & 4 & - & 3 & 1 & - \\
\hline Ice-cream & 85 & $5(5.9)$ & 5 & - & 1 & 1 & - & - & - \\
\hline Commercial ice-cream & 30 & - & - & - & - & - & - & - & - \\
\hline Traditional ice-cream & 55 & $5(9.1)$ & 5 & - & 1 & 1 & - & - & - \\
\hline Butter & 57 & $3(5.3)$ & 2 & 1 & 2 & 1 & - & - & 1 \\
\hline Commercial butter & 20 & - & - & - & - & - & - & - & - \\
\hline Traditional butter & 37 & $3(8.1)$ & 2 & 1 & 2 & 1 & - & - & 1 \\
\hline Cream & 36 & $2(5.6)$ & 2 & - & - & - & - & - & - \\
\hline Commercial cream & 10 & - & - & - & - & - & - & - & - \\
\hline Traditional cream & 26 & $2(7.7)$ & 2 & - & - & - & - & - & - \\
\hline Yoghurt & 30 & - & - & - & - & - & - & - & - \\
\hline Commercial yoghurt & 11 & - & - & - & - & - & - & - & - \\
\hline Traditional yoghurt & 19 & - & - & - & - & - & - & - & - \\
\hline Kashk $^{\mathrm{b}}$ & 24 & - & - & - & - & - & - & - & - \\
\hline Commercial kashk & 8 & - & - & - & - & - & - & - & - \\
\hline Traditional kashk & 16 & - & - & - & - & - & - & - & - \\
\hline Iranian dough ${ }^{\mathrm{c}}$ & 25 & - & - & - & - & - & - & - & - \\
\hline Commercial doogh & 10 & - & - & - & - & - & - & - & - \\
\hline Traditional doogh & 15 & - & - & - & - & - & - & - & - \\
\hline Total & 347 & $20(5.8)$ & $16(80)$ & $4(20)$ & $7(35)$ & 2 & 3 & 1 & 1 \\
\hline
\end{tabular}

${ }^{\mathrm{a}}$ Made from raw sheep or cow milk. ${ }^{\mathrm{b}} \mathrm{A}$ dairy product prepared by beating unflavored yogurt until smooth, and then diluting with water to a consistency similar to whole milk; it is also called yogurt soda. ${ }^{\mathrm{c}} \mathrm{A}$ dairy product prepared by prolonged boiling yogurt.

detected in only 4 traditional cheeses. Type A + D enterotoxin was found in 1 butter (Table 2). No SEs was identified in cream samples.

Table 3 shows the results of PCR assays for the detection of genes encoding the SEA-SEJ toxins. Of the 20 strains of $S$. aureus tested, $16(80.0 \%)$ were positive for one or more SE genes and 9 different genotypes were observed.
Five strains possessed only one type of toxin gene and the reimaining isolates harbored more than one toxin genes. The most commonly detected genes were seg + sei (20.0\%), sej (15.0\%), sec $+\operatorname{sej}(15.0 \%), \operatorname{sei}+\operatorname{seh}(10.0 \%)$, sea + sed $+\operatorname{sej}(5.0 \%)$, sea + sej + sei $(5.0 \%)$, and sea + sec $+\operatorname{seh}(5.0 \%)$. No see or seb gene was detected in any of the isolates.

Table 3 - Detection rates of genotypes of Staphylococcus aureus isolated from traditional dairy products according to sea, seb, sed, see, seg, she, sei and sej genes.

\begin{tabular}{lccccc}
\hline Genotypes & Cheese $(\mathrm{N}=10)$ & Ice-cream $(\mathrm{N}=5)$ & Butter $(\mathrm{N}=3)$ & Cream $(\mathrm{N}=2)$ & Total $(\mathrm{N}=20)$ \\
\hline Sea & - & - & 1 & - & 1 \\
sej & 2 & 1 & - & - & 3 \\
Sec, sej & 3 & - & - & - & 3 \\
Seg, sei & 2 & - & 1 & 1 & 4 \\
Sei, seh & - & 1 & - & - & 2 \\
Sea, seg, sei & - & 1 & - & - & 1 \\
Sea, sed, sej & - & - & - & - & 1 \\
Sea, sec seg, seh & 1 & - & & & 1 \\
\hline
\end{tabular}


On comparing the data relative to the strains isolated from chesses, ice cream, butter, and cream, 8 of the 10 $(80.0 \%)$ strains isolated from cheese samples were se gene positive in which the sec genes were found more frequently. Three of the $5(60.0 \%) S$. aureus isolated from ice-cream and all of the $S$. aureus isolated from butter and cream samples were se gene positive.

The resistance pattern of $S$. aureus isolates to 14 antimicrobial agents tested in this study is shown in Table 4. Most of the isolates $(95.0 \% ; n=19)$ were resistant to one or more antimicrobial agent. Three isolates (15.0\%) were resistant to single antibiotic and 7 isolates (35.0\%) showed resistance to 2 antimicrobial agents. Multiresistance which was defined as resistance to 3 or more of antimicrobial agents tested was found in $45.0 \%$ of $S$. aureus isolates.

\section{Results and Discussion}

In the present study, 20 of the 220 traditional (9.1\%) dairy product samples were positive for $S$. aureus. No $S$. aureus was isolated from 127 commercial dairy products and the difference was statistically significant $(\mathrm{p}<0.05)$. The high occurrence of $S$. aureus in traditional dairy products could be due to environmental contamination with infected animal wastes or unsanitary food production and storage practices. However, this could be also due to the use of unpasteurized milk because the shedding of bacteria from the infected mammary glands of dairy animals is most likely the primary source of $S$. aureus contamination of

Table 4 - Antimicrobial resistance profiles of Staphylococcus aureus isolated from dairy product samples in Iran.

\begin{tabular}{lc}
\hline Antimicrobial agent & S. aureus $(\mathrm{N}=20)$ \\
\hline Ampicillin & $11(55.0 \%)$ \\
Cephalotin & $0(0.0 \%)$ \\
Chloramphenicol & $2(10.0 \%)$ \\
Ciprofloxacin & $1(5.0 \%)$ \\
Clindamycin & $1(5.0 \%)$ \\
Enrofloxacin & $3(15.0 \%)$ \\
Erythromycin & $5(25.0 \%)$ \\
Gentamicin & $3(15.0 \%)$ \\
Methicillin & $0(0.0 \%)$ \\
Oxacillin & $5(25.0 \%)$ \\
Penicillin G & $6(30.0 \%)$ \\
Tetracycline & $8(40.0 \%)$ \\
Trimethoprim-sulfametoxazole & $5(25.0 \%)$ \\
Vancomycin & $0(0.0 \%)$ \\
Total & \\
Resistance to 1 antimicrobial & $3(15.0 \%)$ \\
Resistance to 2 antimicrobials & $7(35.0 \%)$ \\
Resistance to > 2 antimicrobials & $9(45.0 \%)$ \\
\hline
\end{tabular}

milk and dairy products. While commercials products are produced with pasteurized milk under sanitary condition.

S. aureus count was determined about $10^{3} \mathrm{cfu} / \mathrm{g}$ in 20 samples period. In 3 of sheep cheese, and 1 butter samples, $S$. aureus counts were above $10^{5} \mathrm{cfu} / \mathrm{g}$ (Table 2). The prevalence of $S$. aureus in traditional cheese, ice cream, cream and butter was $11.1 \%, 5.9 \%, 5.6 \%$, and $5.3 \%$, respectively, which is comparable with those reported by Manfreda et al (2005), Ertas et al. (2010), Bostan et al. (2006), and Pelisser et al. (2009). Necidová et al. (2009) reported, S. aureus count higher than $10^{5} \mathrm{cfu} / \mathrm{g}$ is unsuitable for the production of cheese. Staphylococcal counts should reach approximately $10^{6} \mathrm{cfu} / \mathrm{g}$ to produce enterotoxin (Necidová et al., 2009, Pelisser et al., 2009).

In this study, $35.0 \%$ of isolated $S$. aureus strains produced classical enterotoxins. This result is in agreement with those reported by other investigators (Morandi et al., 2007, Normanno et al., 2005). Most of the isolated strains produced SEA, SED, and SEC. Our data show that SEs and se genes are in close correlation with the $S$. aureus strain origin. For example, a higher ratio of strains isolated from traditional sheep and goat cheeses produced mainly SEC, while the strains isolated from other dairy products made from cow milk produced SEA and SED. These results are in agreement with the data reported from other countries (Akineden et al., 2008, Loncarevic et al., 2005, Morandi et al., 2005, Rall et al., 2008, Scherrer et al., 2004). Of the 20 strains of $S$. aureus tested, $17(85.0 \%)$ were positive for one or more SE genes and 8 different genotypes were observed. Five strains possessed one type of toxin gene, while the reimaining 12 harbored more than one toxin genes. The most commonly detected genes were seg + sei, sej, sec + $s e j, s e i+s e h, s e a+s e d+s e j, s e a+s e j+s e i$, and $s e a+s e c+$ seh. Similar results were presented by Normanno et al. (2005), Manfreda et al. (2005), and Tkacikova et al. (2003). In contrast, the incidence of $S$. aureus and their SEs was reported relatively high by several authors (Fotta et al., 2000, Holeckova et al., 2002) when compared with our results. Variation in the results reported in other studies may be a result of different sampling techniques employed, seasonal effects, and/or laboratory methodologies employed in different studies.

$S$. aureus strains are known to be frequently resistant to antibiotic therapy due to their capacity to produce an exopolysaccharide barrier and because of their location within microabscesses, which limit the action of drugs (Gündogan et al., 2006). The resistance pattern of $S$. aureus isolates to 12 antimicrobial agents tested in this study is shown in Table 3. Most of the 20 S. aureus isolates (95.0\%) were resistant to one or more antimicrobial agent. Resistance to ampicillin was the most common finding, followed by resistance to tetracycline, penicillin $\mathrm{G}$, oxacillin, eritromycin, trimethoprim-sulfametoxazole, enrofloxacin, gentamycin, chloramphenicol, clindamycin, and ciprofloxacin. All isolates tested for antibiotic sensitivity were susceptible 
to methicillin cephalotin and vancomycin. These results are comparable to those reported by other investigators (Gündogan et al., 2006, Normanno et al., 2007, Peles et al., 2007, Pereira et al., 2009, Pesavento et al., 2007). The results of antimicrobial resistance found in this study are correlated to antibiotics that are being used to treat infection in food animals in Iran. A national monitoring program for antibiotic resistance, including both human and food isolates, is needed In Iran.

National legislation of $S$. aureus in milk and dairy products which is $10^{2} \mathrm{cfu} / \mathrm{g}$. S. aureus in about $9 \%$ of traditional dairy products found to be above which shows the importance of some traditional dairy products as potential sources of $S$. aureus infection in people who consume traditional dairy products. We recommend that coordinated actions are needed to reduce or eliminate the risks posed by this organism at a number of stages in the food chain. These include Good Agricultural Practice, Good Manufacturing Practice and Hazard Analysis of Critical Control Points at every stages of the meat supply chain, from the farm, to the retailer, and those involved with the handling and processing of raw milk products in the home environment.

\section{Acknowledgments}

The authors would like to thank Hassan Momtaz, Manochehr Momeni and Majed Riahi for the sincere help in performing technical parts of the project.

\section{References}

Akineden Ö, Hassan AA, Schneider E, Usleber E (2008) Enterotoxigenic properties of Staphylococcus aureus isolated from goats' milk cheese. Int J Food Microbiol 124:211-216.

Atichou M, Henkens R, Sultana A, Ulrich R, Ibrahim M (2004) Detection of Staphylococcus aureus enterotoxin A and B genes with PCR-EIA and a hand-held electrochemical sensor. Mol Cell Probes 18:373-377.

Becker H, Bürk C, Märtlbauer E (2007) Staphylokokken-Enterotoxine: Bildung, Eigenschaften und Nachweis. J Verbr Lebensm 2:171-189.

Bostan K, Cetin O, Buyukunal SK, Ergun O (2006) The presence of Staphylococcus aureus and staphylococcal enterotoxyns in ready-to-cook meatballs and whyte pyckled cheese. J Fac Vet Med Istanbul Univ 32:31-39.

Clinical and Laboratory Standards Institute (2006) Performance Standards for Antimicrobial Disk Susceptibility Tests, Approved Standard. M2-A9. Ninth Edition. Clinical and Laboratory Standards Institute, Wayne.

Ertas N, Gonulalan Z, Yildirim Y, Kum E (2010) Detection of Staphylococcus aureus enterotoxins in sheep cheese and dairy desserts by multiplex PCR technique. Int J Food Microbiol 142:74-77.

Fotta M, Federicova J, Gondol L, Kalinicova V, Heleckova B (2000) Occurrence of enterotoxigenic strains of Staphylococcus aureus. Slov Vet Cas 25:291-293.

Gündogan N, Citak S, Turan E (2006) Slime production, DNAse activity and antibiotic resistance of Staphylococcus aureus isolated from raw milk, pasteurized milk and ice cream samples. Food Control 17:389-392.

Holeckova B, Holoda E, Fotta M, Kalinocova V, Gondol C, Grolmus J (2002) Occurrence of enterotoxigenic Staphylococcus aureus in food. Ann Agric Environ Med 9:179-182.

Huong BTM, Mahmud ZH, Neogi SB, Kassu A, Nhien NV, Mohammad A, Yamato M, Ota F, Lam NT, Dao HTA, Khan NC (2010) Toxigenicity and genetic diversity of Staphylococcus aureus isolated from Vietnamese ready-to-eat foods. Food Control 21:166-171

Jay MJ, Loessner JM, Golden AD (2005) Staphylococcal gastroenteritis. In: Modern Food Microbiology. 7th edition. Springer Science, New York, pp 545-560.

Le Loir Y, Baron F, Gautier M (2003) Staphylococcus aureus and food poisoning. Genet Mol Res 2:63-67.

Loncarevic S, Jørgensen HJ, Løvseth A, Mathisen T, Rørvik LM (2005) Diversity of Staphylococcus aureus enterotoxin types within single samples of raw milk and raw milk products. J Appl Microbiol 98:344-350.

Manfereda G, Mioni R, De Cesare A (2005) Surveillance and carcterization of enterotoxigenic Staphylocci in foods of animal origin collected in the Veneto Region. Vet Res Comm 29:331-333

Morandi S, Brasca M, Lodi R, Cremonesi P, Castiglioni B (2007) Detection of classical enterotoxins and identification of enterotoxin genes in Staphylococcus aureus from milk and dairy products. Vet Microbiol 124:66-72.

Necidova L, Stastkova Z, Pospisilova M, Janstova B, Strejcek J, Duskova M, Karpiskova R (2009) Influence of soft cheese technology on the growth and enterotoxin production of Staphylococcus aureus. Czech J Food Sci 27:127-133.

Normanno G, Firinu A, Virgilio S, Mula G, Dambrosio A, Poggiu A, Decastelli L, Mioni R, Scuota S, Bolzoni G, Di Giannatale E, Salinetti AP, La Salandra G, Batoli M, Zuccon F, Pirino T, Sias S, Parisi A, Quaglia NC, Celano GV (2005) Coagulase-positive staphylococci and Staphylococcus aureus in food products marketed in Italy. Int J Food Microbiol 98:73-79.

Normanno TG, La Salandra G, Dambrosio A, Quaglia NC, Corrente M, Parisi A, Santagada G, Firinu A, Crisetti E, Celano GV (2007) Occurrence, characterization and antimicrobial resistance of enterotoxigenic Staphylococcus aureus isolated from meat and dairy products. Int J Food Microbiol 115:290-296

Peles F, Wagner M, Varga L, Hein I, Rieck P, Gutser K, Keresztúri P, Kardos G, Turcsányi I, Béri B, Szabó A (2007) Characterization of Staphylococcus aureus strains isolated from bovine milk in Hungary. Int J Food Microbiol 118:186-193.

Pelisser MR, Klein CS, Ascoli KR, Zotti TR, Arisil ACM (2009) Occurrence of Staphylococcus aureus and multiplex PCR detection of classic enterotoxin genes in cheese and meat products. Braz J Microbiol 40:145-148.

Pereira V, Lopes C, Castro A, Silva J, Gibbs P, Teixeira P (2009) Characterization for enterotoxin production, virulence factors, and antibiotic susceptibility of Staphylococcus aureus isolates from various foods in Portugal. Food Microbiol 26:278-282

Pesavento G, Ducci B, Comodo N, Nostro AL (2007) Antimicrobial resistance profile of Staphylococcus aureus isolated from raw meat: A research for methicillin resistant Staphylococcus aureus (MRSA). Food Control 18:196-200. 
Rahimi E, Ghasemian Safai H (2010) Detection of classical enterotoxins of Staphylococcus aureus strains isolated from bovine subclinical mastitis in Isfahan, Iran. Vet Microbiol 141:393-394.

Rall VL, Vieira FP, Rall R, Vieitis RL, Fernandes AJr, Candeias JM, Cardoso KF, Araújo JPJr (2008) PCR detection of staphylococcal enterotoxin genes in Staphylococcus aureus strains isolated from raw and pasteurized milk. Vet Microbiol 10:408-413.

Sambrook J, Russell DW (2001) Molecular Cloning: A Laboratory Manual. 3rd edition. Cold Spring Harbor Laboratory Press, Cold Spring Harbor.

Sandel M, McKillip J (2004) Virulence and recovery of Staphylococcus aureus relevant to the food using improvement on traditional approaches. Food Control 15:5-10.
Scherrer D, Corti S, Muehlherr JE, Zweifel C, Stephan R (2004) Phenotypic and genotypic characteristics of Staphylococcus aureus isolates from raw bulk-tank milk samples of goats and sheep. Vet Microbiol 101:101-107.

Tkacikova L, Tesfaye A, Mykula I (2003) Detection of the genes for Staphylococcus aureus enterotoxin by PCR. Acta Vet Brunensis 72:627-630.

Zouharova M, Rysanek D (2008) Multiplex PCR and RPLA identification of Staphylococcus aureus enterotoxigenic strains from bulk tank milk. Zoonoses Public Health 55:279-330.

All the content of the journal, except where otherwise noted, is licensed under a Creative Commons License CC BY-NC. 